\title{
Evaluation of Functional Outcome Following Open Reduction and Internal Fixation of Proximal Humerus Fractures Using Philos Plate: A Prospective Study
}

\author{
Dr. Govind Kumar Gupta ${ }^{1}$, Dr. Sudha Rani ${ }^{2}$, Dr. Vinit Vivek ${ }^{3}$, Dr. Umashanker Prasad Keshri ${ }^{4 *}$
}

${ }^{1}$ Associate Professor, Department of Orthopaedics, RIMS Ranchi, Rims Cir, Indraprasth Colony, Bariatu, Ranchi, Jharkhand 834009, India

${ }^{2}$ Assistant Professor \& HOD, Department of Anatomy, Hazaribag Medical College, Kolghatti, Hazaribagh, Jharkhand 825301, India

${ }^{3}$ Senior Resident, Department of Orthopaedics, Palamu Medical College, Panki, Road, Daltonganj, Jharkhand 822101, India

${ }^{4}$ Professor, Department of Pharmacology, RIMS, Ranchi, Rims Cir, Indraprasth Colony, Bariatu, Ranchi, Jharkhand 834009, India

DOI: $10.36347 / \mathrm{sajb} .2020 . \mathrm{v} 08 \mathrm{i} 06.007$

| Received: 16.06.2020 | Accepted: 23.06.2020 | Published: 26.06.2020

*Corresponding author: Dr. Umashanker Prasad Keshri

Abstract

Original Research Article

Proximal humeral fractures are the second most common fractures of the upper extremity and $20 \%$ of them require surgical fixation either because they needs better shoulder mobility or because their fracture is more severe. PHILOS plate promises to provide good fixation and stability. This prospective study aims to evaluate the functional outcome in the subjects following surgery. After obtaining due ethical clearance, a prospective study was conducted from January 2017 to September 2018. Thirty patients were selected. Fracture was classified using NEER'S Classification. All the fractures were approached by Delto pectoral approach and fixation done under fluoroscopic guidance. Patients were followed up at 6 weeks, 3, 6 and 12 months with radiographical evaluation and clinical examination and outcome. All patients at their final assessment underwent radiological and functional evaluation using the CONSTANT score. Based on NEER'S classification, 8patients (26.7\%) had 2 part fracture, 12patients $(40.0 \%)$ had 3 part fracture and 10patients (33.3\%) had 4 part fracture. 1 patient had delayed union, 1 patient had non union, 2 patients developed stiffness of shoulder, 1 patient had a superficial infection and 1 patient had varus malunion. We assessed the final functional outcome with CONSTANT-MURLEY score and found that $7(20.0 \%)$ patients had excellent, 11(36.7\%) patients had good, $7(23.3 \%)$ patients had moderate and $5(16.7 \%)$ patients had poor outcome. The mean constant score (mean \pm s.d.) of patients was 70.1000 \pm 13.0816 . Surgical management of fracture proximal humerus with PHILOS plating has a good functional outcome. However, proper patient selection, thorough knowledge of the anatomy and biomechanical principles are the pre-requisites for a successful surgery.

Keywords: PHILOS, CONSTANT Score, Proximal humerus, Neer's classification.

Copyright @ 2020: This is an open-access article distributed under the terms of the Creative Commons Attribution license which permits unrestricted use, distribution, and reproduction in any medium for non-commercial use (NonCommercial, or CC-BY-NC) provided the original author and source are credited

\section{INTRODUCTION}

Proximal humeral fractures are the second most common fractures of the upper extremity accounting for $4 \%$ to $5 \%$ of all fractures [1]. The incidence of proximal fractures is $26 \%$ of all humerus fractures, are the commonest fractures in elderly population, which ranks the third and the first and second being, hip and distal radius fractures respectively. Proximal humerus involves head, greater tuberosity, lesser tuberosity and proximal one fourth of the shaft. Fracture of proximal humerus occurs most commonly in elderly patients due to osteoporosis and less frequently in young adults due to high energy trauma [2].
Most of the proximal humerus fractures, in younger as well as in the elderly patients, are stable \& slightly or non-displaced, can be treated non operatively [3]. These comprise nearly $80 \%$ of the proximal humerus fractures. The rest of $20 \%$ requires surgical fixation either because they needs better shoulder mobility or because their fracture is more severe. Neer's classification distinguishes between the number of displaced fragments with displacement defined as greater than $45^{\circ}$ of angulation or $>1 \mathrm{~cm}$ of separation. These type of fractures require stable fixation.

Difficulties have been multifactorial, including osteoporotic bone, angular instability, implant impingement, loss of reduction and backing out of 
screws. The indication for fixing such a fracture depends on the fracture pattern, quality of bone and age and activity of the patient.

Conservative treatment is usually associated with nonunion, malunion and avascular necrosis resulting in a painful dysfunction [4].

The goal is to achieve near anatomical reduction and stabilization so as to achieve early mobilization.

The surgical modalities used are transosseous suture fixation, closed reduction and percutaneous fixation, open reduction and internal fixation with conventional plates, locking plate fixation, intramedullary fixation and hemiarthroplasty which have shown to have mixed results [3-6]. Complications of these techniques include cutout or backout of screws and plates, avascular necrosis, non-union, malunion, nail migration, impingement of rotator cuff and impingement syndrome. Insufficient anchorage from conventional implant may lead to early loosening and failure, especially in osteoporotic bones. Every fixation has its own complication. The proximal humerus with poor cancellous bone quality especially in older patients, results in high risk of failure of fixation with conventional plating system $[4,5,6]$. Pre-contoured locking compression plates are fixed angled devices which prevent subsidence in the metaphyseal areas [7-9]. These plates alleviate the risk of malreduction and preserve the blood supply to the bone.

The PROXIMAL HUMERUS INTERNAL LOCKING SYSTEM (PHILOS) plate has been introduced to reduce these complications especially in older osteoporotic individual. PHILOS plate provides rigid fixation and greater angular stability than do conventional implants. It works as a locked internal fixator and provides better anchorage of screws in osteoporotic bones, with good functional outcomes. Even minimally displaced fracture can be treated with PHILOS plate to early mobilise the fracture thereby to avoid shoulder stiffness. Highly communited $3 \& 4$ parts fractures can be reconstructed with rotator cuff sutural ties with plate and thereby enhance the functional outcome. This study enlightens the functional outcome of management of the fracture of humerus involving the proximal part, with PHILOS plate [10].

\section{MATERIALS \& METHODS}

After obtaining due ethical clearance, a prospective study was conducted from January 2017 to September 2018. Thirty patients were selected based on the following criteria.

\section{Inclusion Criteria}

1. Patients with displaced proximal humerus fracture, (Neer's two, three and four part fractures.)

2. Patients undergoing revision surgery for failure implants.

3. Patients who have given consent to this study.

\section{Exclusion Criteria}

1. Pathological fractures from primary or metastatic tumours

2. Patients age less than 18 years

3. Open fractures

4. Polytrauma

5. Failure of conservative treatment

6. Patient who did not give consent for study

Age, profession and sex of the patient, mode of injury, severity of the injury, associated injuries, time since injury and their function demands were noted down. Diagnosis was confirmed with plain radiographs. Intra-articular extent of fracture geometry was assessed with thin slice of CT scan in doubtful cases. Fracture was classified using NEER'S Classification and planned pre-operatively according to it. Patients were treated with analgesics, U- slab till surgery. Co-morbidities were treated accordingly. Routine investigations were carried out in order to get fitness for surgery. Consent of the patient was taken.

All the fractures were approached by Delto pectoral approach and fixation done under fluoroscopic guidance. Intra-operative events, difficulties and complications, post-operative radiological evaluations and bony union were noted. Post-operatively limb was immobilized in arm pouch; mobilization was started in the second week with pendulum exercises as per patient's tolerance.

Immediate post-op X-Rays were done routine A-P and axillary view to assess the reduction of fracture and stability of fixation. Most of the suture removal was done on 10th day. Patients were discharged with arm pouch and advise to continue pendulum exercises.

Patients were followed up at 6 weeks, 3, 6 and 12 months with radiographical evaluation and clinical examination and outcome. All patients at their final assessment underwent radiological and functional evaluation using the CONSTANT score.

The Constant score assigns points for Pain, Range of movements, Power and Activities of daily living. Muscle strength was measured with use of a $1 \mathrm{~kg}$ weight in the patient's hand and the shoulder in $90^{\circ}$ of abduction, or, if $90^{\circ}$ could not be reached, in maximum active abduction as described by Constant. 
The Constant score was graded as

Poor (0 to 55points),

Moderate (56to 70points),

Good (71 to 85points),

Excellent (86to 100points).

\section{RESULTS}

Of the thirty patients, 4 belonged to the age group of 21-30years, 7 were inthe age group of 31-40 years, 9 were in the age group of 40-50 years, and those belonging to the age group of 51-60 and 61-70 years were 8 and 2 respectively. The mean age was $44.0333 \pm$ 11.2449 years. 21 patients $(70 \%)$ were male whereas $9(30 \%)$ were female patients. The ratio of Male to Female was 2.3:1.

Three patients $(10.0 \%)$ had assault as mode of injury , 9 patients (30.0\%) had sustained fall and 18 patients $(60.0 \%)$ had met with road traffic accident (RTA).RTA was the most common mode of injury observed in our series.10 patients had sustained a fracture on the left, as compared to 20 patients with the involvement of right side.

Based on NEER'S classification, 8 patients (26.7\%) had 2 part fracture, 12patients $(40.0 \%)$ had 3 part fracture and 10patients $(33.3 \%)$ had 4 part fracture.
The mean duration of surgery (mean \pm s.d.) was $112.6667 \pm 24.7656$ minutes. The mean blood loss (mean \pm s.d.) of patients was $178.3333 \pm 65.2361 \mathrm{ml}$. The mean duration of stay at hospital (mean \pm s.d.) of patients was $10.4333 \pm 1.2780$ days.

1 patient had delayed union, 1 patient had non union, 2 patients developed stiffness of shoulder, 1 patient had a superficial infection and 1 patient had varusmalunion. Association of complication and outcome was statistically significant $(\mathrm{p}=0.0127)$ which implies that patents who suffered complications reported an overall poor functional outcomes.

Table-1: Distribution of Complication

\begin{tabular}{|l|l|l|}
\hline COMPLICATION & Frequency & Percent \\
\hline DELAYED UNION & 1 & $3.3 \%$ \\
\hline PLATE IMPINGEMENT & 1 & $3.3 \%$ \\
\hline $\begin{array}{l}\text { STIFFNESS OF } \\
\text { SHOULDER }\end{array}$ & 2 & $6.7 \%$ \\
\hline $\begin{array}{l}\text { SUPERFICIAL } \\
\text { INFECTION }\end{array}$ & 1 & $3.3 \%$ \\
\hline VARUS MALUNION & 1 & $3.3 \%$ \\
\hline
\end{tabular}
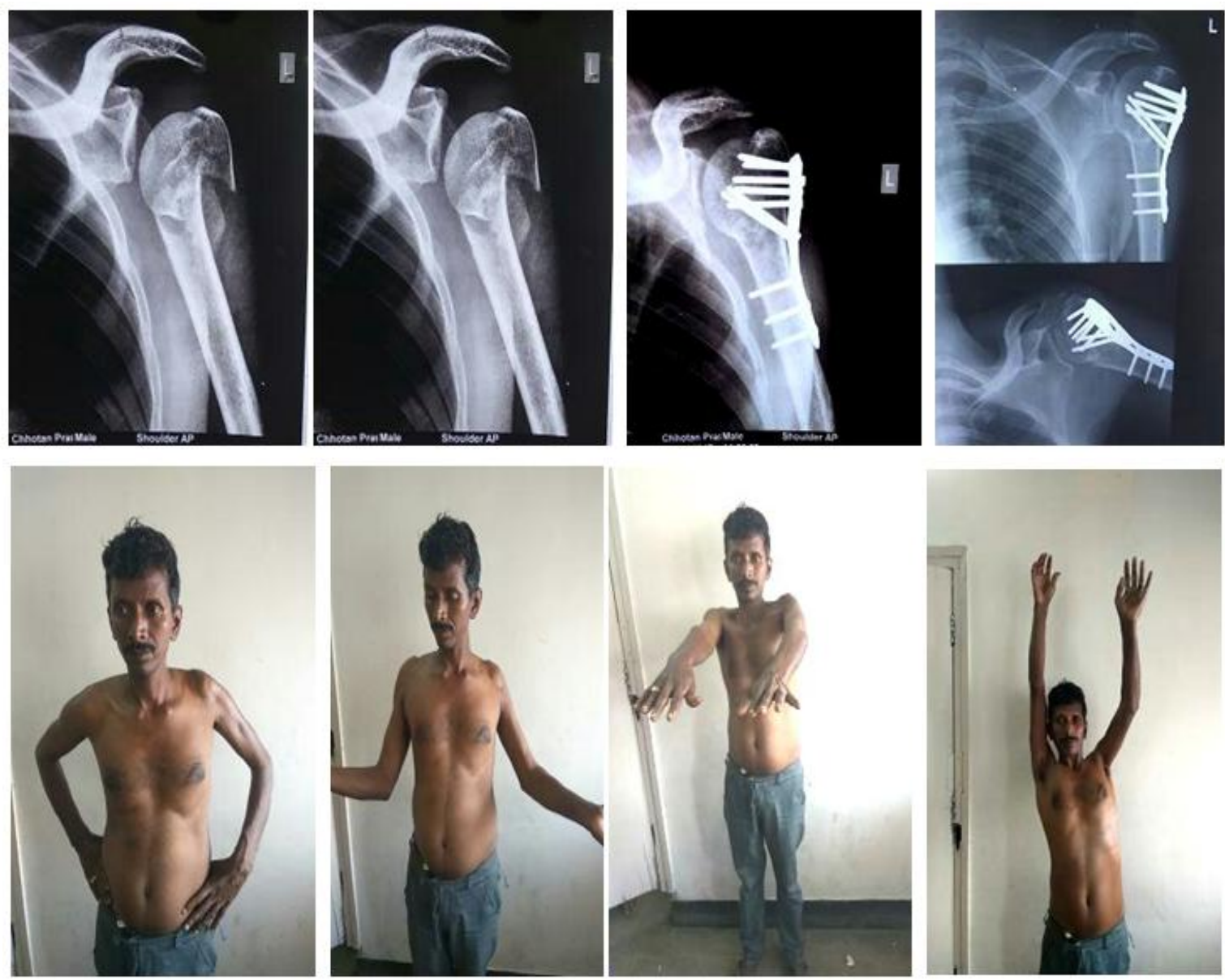
In the present study the time taken for radiological union was 10 weeks in $4(13.3 \%)$ patients, 11 weeks in $3(10.0 \%)$ patients, 12 weeks in $12(43.3 \%)$ patients, 13 weeks in $6(20.0 \%)$ patients, 14 weeks in $2(6.7 \%)$ patients, $1(3.3 \%)$ patients 15 weeks, and 18 weeks in $1(3.3 \%)$ patients. However, the mean union time didn't significantly affect the final outcome $(\mathrm{p}=0.0501)$.

We assessed the final functional outcome with CONSTANT-MURLEY score and found that 7(20.0\%) patients had excellent, 11(36.7\%) patients had good, $7(23.3 \%)$ patients had moderate and $5(16.7 \%)$ patients had poor outcome. The mean constant score (mean \pm s.d.) of patients was $70.1000 \pm 13.0816$.

Patients reporting a poor outcome, had delayed union (1 patient), 2(60\%) with stiff shoulder and 1(20\%) patient had varusmalunion. Association of complication vs. outcome was statistically significant $(\mathrm{p}=0.0127)$.

Excellent outcome was found to be associated with 2 part fractures, the mean being $2.8571 \pm .6901$ parts. Poor outcome was frequently associated with 4 part fractures $($ mean \pm s.d. $=3.8000 \pm .4472)$. The association of mean Neer's type and outcome was statistically significant $(\mathrm{p}=0.0384)$.

\section{DISCUSSION}

The mean age (mean \pm s.d.) of patients in this study was $44.0333 \pm 11.2449$ years, range (21-65 years. The average age incidence was $54.3 \pm 5.8$ years in the study done by Doshi $\mathrm{C}$ et al., [11] and 38 years (range 24-68) in the study done by Kumar GK et al., [12] 58 years(range 22-78) in the study done by Sreen $\mathrm{S}$ et al., [13] 49.24 years in the study done by Bansal V et al., [15].

Literature reveals predominance of proximal humeral fractures in females in an elderly age group 40. However, in the present study, $9(30.0 \%)$ patients were females and $21(70.0 \%)$ patients were males with male to female ratio being 2.3: 1 .

The mean duration of surgery (mean \pm s.d.) of patients was $112.6667 \pm 24.7656$ min which was consistent with the mean duration of surgery in the study done by Doshi C et al., [11] was $94 \pm 10.2$ minutes.

The incidence of complications were comparable to the previous studies as depicted in the underlying table.

Table-2: Comparison of complication rates among similar studies

\begin{tabular}{|l|l|l|l|}
\hline COMPLICATION & Kumar GK et al., $[\mathbf{1 2}]$ & Bansal V et al., $[\mathbf{1 5}]$ & OUR STUDY \\
\hline STIFFNESS OF SHOULDER & 00 & $8 \%$ & $2(6.7 \%)$ \\
\hline PLATE IMPINGEMENT & 1 & $4 \%$ & $1(3.3 \%)$ \\
\hline POST-OP INFECTION & 1 & $12 \%$ & $1(3.3 \%)$ \\
\hline DELAYED UNION & 00 & 00 & $1(3.3 \%)$ \\
\hline VARUS MALUNION & 4 & $20 \%$ & $1(3.3 \%)$ \\
\hline OSTEONECROSIS OF HEAD OF HUMERUS & 00 & $8 \%$ & 00 \\
\hline SCREW PERFORATION & 1 & $16 \%$ & 00 \\
\hline PULL OUT OF SCREWS & 00 & $4 \%$ & 00 \\
\hline
\end{tabular}

The mean union time (mean \pm s.d.) was $12.2666 \pm 1.6174$ weeks whichis consistent with the mean union time in other studies as shown in the table below:

Table-3: Mean union time

\begin{tabular}{|l|l|}
\hline STUDY & UNION TIME (WEEKS) \\
\hline Doshi C et al., $[11]$ & $12 \pm 4.6$ \\
\hline Kumar GK et al., $[12]$ & 12 \\
\hline Sreen S et al., $[13]$ & Range ( 8-12) \\
\hline Our study & $12.2666 \pm 1.6174$ (range $10-18)$ \\
\hline
\end{tabular}

We assessed the final functional outcome with CONSTANT-MURLEY score and found that according to outcome, $7(20.0 \%)$ patients had excellent, 11(36.7\%) patients had good, $7(23.3 \%)$ patients had moderate and $5(16.7 \%)$ patients had poor outcome. We found that the mean constant score (mean \pm s.d.) of patients was $70.1000 \pm 13.0816$.
In the study by Kumar GK et al., [12], at the final follow-up the mean Constant-Murley score was 79 (range 50-100) and the results were excellent in 25 patients, good in 13 patients, fair in 6 patients and poor in 5 patient. Out of 30 cases, excellent result in 7 cases, Good in16 cases Satisfactory in 5 cases and Poor in 2 cases were reported by Sreen $\mathrm{S}$ et al., [13] and outcomes were excellent in $16 \%$, good in $44 \%$, fair in $16 \%$ while poor in $24 \%$ in the study done by Bansal V et al., [15]. 
Rao TV et al., [16] found that excellent and satisfactory results were found in $80 \%$ of patients with unsatisfactory results in $20 \%$ according to Neer's criteria. Sharma V et al., [14] found functional outcome based on the Constant scoring system showed excellent results in $20(50 \%)$, good in eight $(20 \%)$, and moderate in eight $(20 \%)$ patients. Four (10\%) patients had poor functional results.

\section{CONCLUSION}

Surgical management of fracture proximal humerus with PHILOS plating has a good functional outcome. However, proper patient selection, thorough knowledge of the anatomy and biomechanical principles are the pre-requisites for a successful surgery. From our study, it can be safely recommended that for proximal humerus fractures PHILOS plating is a good choice of surgical treatment.

\section{Conflict of Interest: None.}

\section{REFERENCES}

1. Cofield RH. Comminuted fractures of the proximal humerus. Clinical orthopaedics and related research. 1988 May; (230):49-57.

2. Carofino BC, Leopold SS. Classifications in brief: the Neer classification for proximal humerus fractures. Clinical orthopaedics and related research. 2013 January; 471(1):39-43.

3. Jo MJ, Gardner MJ. Proximal humerus fractures. Current reviews in musculoskeletal medicine. 2012 September; 5(3): 192-8.

4. Bentley G. European Instructional Lectures: Volume 9, 2009; 10th EFORT Congress, Vienna, Austria. Springer Science \& Business Media. 2009; 81.

5. "Humerus Fracture (Upper Arm Fracture) Johns Hopkins Medicine Health Library". www.hopkinsmedicine.org. Retrieved 7 November 2018.

6. Handoll HH, Brorson S. Interventions for treating proximal humeral fractures in adults. The Cochrane database of systematic reviews. 2015 November

\section{1; (11): CD000434.}

7. Handoll $\mathrm{HH}$, Brorson S. Interventions for treating proximal humeral fractures in adults. Cochrane Database of Systematic Reviews. 2015(11).

8. Agarwal SC, Grynpas MD. Bone quantity and quality in past populations. Anat Rec. 1996;246:423-432.

9. Allen JP. The Art of Medicine in Ancient Egypt. New York, NY: The Metropolitan Museum of Art; 2005.

10. Bourke JB. Trauma and degenerative diseases in ancient Egypt and Nubia. J Hum Evol. 1972; 1:225-232.

11. Doshi C, Sharma GM, Naik LG, Badgire KS, Qureshi F. Treatment of Proximal Humerus Fractures using PHILOS Plate. Journal of clinical and diagnostic research: JCDR. 2017 Jul; 11(7):RC10.

12. Kumar GK, Sharma G, Sharma V, Jain V, Farooque K, Morey V. Surgical treatment of proximal humerus fractures using PHILOS plate. Chinese journal of traumatology. 2014 Oct 1;17(5):279-84

13. Sreen S, Vashisht D, Daroch MS. Management of fracture upper end humerus with proximal humerus internal locking system. International Journal of Research in Medical Sciences. 2017 Apr 26; 5(5):2134-8.

14. Sharma V, Singh B, Khare S. Management of Proximal Humeral Fractures with Proximal Humerus Locking Plate-A Prospective Study: Journal of Orthopaedics, Trauma and Rehabilitation. 2014 Dec1; 18(2):89-93.

15. Bansal V, Sohal HS, Bhoparai RS. Philos plate in proximal humerus fracture-its functional outcome and complications. Int J Orthop. 2015; 2(3):317-22.

16. Rao TV, VenkataswamyK, Venkateshwarlu J, Varma MB. A study on surgical management of proximal humerus fractures by "philos" plate. Journal of evolution of medical and dental sciences-jemds. 2017 Mar 9;6(20):1578-84. 